\title{
Justification of the Double Fed Induction Generator Model for Estimation of the Influence of Wind Power Installations on the Operation Mode of Power Systems
}

\author{
Nikolay Ruban ${ }^{1, \text { a) }}$ Alisher Askarov ${ }^{1, b)}$ and Ekaterina Daminova ${ }^{1, c)}$ \\ ${ }^{1}$ National Research Tomsk Polytechnic University, 634050 Tomsk, Russia. \\ a)Corresponding author: rubanny@tpu.ru \\ b)aba7@tpu.ru \\ c)maybelle@tpu.ru
}

\begin{abstract}
Mathematical modeling of wind power plants is an urgent task, since the degree of their introduction into traditional energy systems is growing every year. At the same time, it is not always possible to obtain information about the processes in the power system. In such cases, it is possible to use the model of the power system. However, since the power systems are enormous, their model is also great, and therefore, with its detailed reproduction, many problems arise. One solution to such problem is to use simplified wind turbine models. The article substantiates the need to use detailed models of wind turbines to analyze their impact on the functioning of the power system.
\end{abstract}

\section{INTRODUCTION}

In the model of a double fed induction generator (DFIG), transients in the rotor are often neglected [1], thus a socalled 3rd-order model is obtained. However, to take into account rotor transients, a detailed simulation of the converter, including semiconductor switches and current control circuits, is required. The result will be time constants that are significantly lower than $100 \mathrm{~ms}$ - a typical minimum time constant used in the specialized software for calculating electromechanical processes, which limits the applicability of such models in the specified software. The resulting model will be much more complex and, therefore, for simplicity, in the specified software of electromechanical processes calculation VSC with current control loops are often represented by current sources. Hybrid simulators do not encounter such a problem $[2,3]$.

However, the 3rd order, as compared to the 5th, of the usual DFIG model is important from the point of view of the behavior of the electric values of the generator and the voltage stability [4]. Leading manufacturers of wind turbines agreed that the use of the 3rd order DFIG model in studies of electromechanical transients leads to incorrect results because the transients of the fundamental frequency in the currents of the machine are ignored. This disadvantage can lead to misleading conclusions regarding the actions of the converter - blocking due to over-current $[5,6]$. This proved that the study of stability, at least, need the 5th order DFIG model.

\section{HIGH ORDER DOUBLE FED INDUCTION GENERATOR MODEL}

The system of equations of the 5th order for DFIG with regard to the direction of the current in the stator and taking into account the axis $\mathrm{d}$, leading the axis $\mathrm{q}$, looks as follows:

$$
u_{d s}=-\frac{d \Psi_{d s}}{d t}-\omega_{s} \Psi_{q s}-R_{s} i_{d s}
$$




$$
\begin{gathered}
u_{q s}=-\frac{d \Psi_{q s}}{d t}+\omega_{s} \Psi_{d s}-R_{s} i_{q s} \\
u_{d r}=-\frac{d \Psi_{d r}}{d t}-s \omega_{s} \Psi_{q r}-R_{r} i_{d r} \\
u_{q r}=-\frac{d \Psi_{q r}}{d t}+s \omega_{s} \Psi_{d r}-R_{r} i_{q r} \\
\frac{d w_{m}}{d t}=\frac{1}{2 H_{m}}\left(T_{m}-T_{e}\right) \\
T_{e}=\Psi_{d s} \cdot i_{q s}-\Psi_{q s} \cdot i_{d s}
\end{gathered}
$$

where $s$ - slip, $u$ - voltage, $i$ - current, $R$ - resistance and $\psi$ - flux linkage. Everything is measured in pu. The subscripts $d$ and $q$ denote, respectively, the direct and quadrature components and the indices $r$ and $s$ for the rotor and stator, respectively. Slip could be found by the formula:

$$
s=1-\frac{p w_{m}}{2 w_{s}}
$$

$\omega_{m}-$ angular frequency of the shaft of the generator turbine (rotor), $p$ - number of poles.

To account for iron losses it is necessary to add an equivalent loss resistance $R i$ and the current through this resistance according to the Fig. 1.

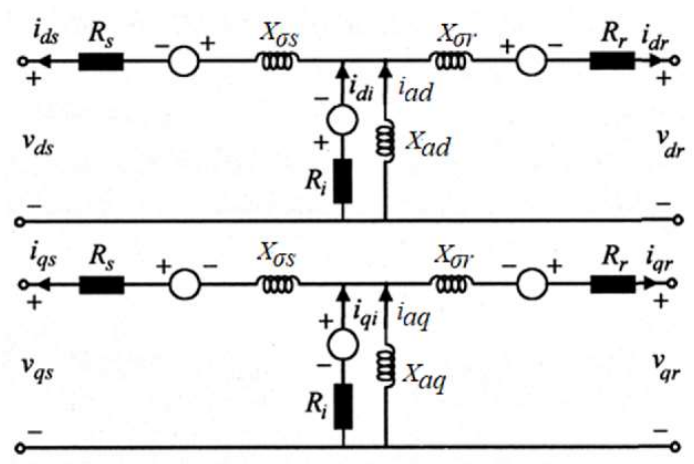

FIGURE 1. Equivalent DFIG scheme

Thus, the complete system of DFIG equations becomes the 7th order model.

$$
\begin{aligned}
& R_{i} i_{d i}=\frac{d \Psi_{\delta d}}{d t}-\omega_{s} \Psi_{\delta q} \\
& R_{i} i_{q i}=\frac{d \Psi_{\delta q}}{d t}+\omega_{s} \Psi_{\delta d}
\end{aligned}
$$

The equations of flux linkage in the air gap are determined according to the expressions:

$$
\Psi_{\delta d}=x_{a d}\left(i_{d s}+i_{d r}+i_{d i}\right)
$$




$$
\Psi_{\delta q}=x_{a q}\left(i_{q s}+i_{q r}+i_{q i}\right)
$$

The equations of the resulting flux linkage in the stator are determined according to the expressions:

$$
\begin{aligned}
& \Psi_{d s}=\Psi_{\delta d}+x_{\sigma s} i_{d s} \\
& \Psi_{q s}=\Psi_{\delta q}+x_{\sigma s} i_{q s}
\end{aligned}
$$

The equations of the resulting flux linkage in the rotor are determined according to the expressions:

$$
\begin{aligned}
& \Psi_{d r}=\Psi_{\delta d}+x_{\sigma r} i_{d r} \\
& \Psi_{q r}=\Psi_{\delta q}+x_{\sigma r} i_{q r}
\end{aligned}
$$

In addition, the saturation of the main magnetic flux will also change the system of equations.

In this case, the saturation of the main flux is taken into account by replacing the reactive resistance in the magnetic circuit with the corresponding value in the saturation state, which is determined according to the expressions:

$$
x_{m s}= \begin{cases}x_{m u}, & i_{m}<0.5 p u \\ K_{m} x_{m u}, & 0.5 p u \leq i_{m} \leq 5 p u\end{cases}
$$

where $K_{m}$ - saturation coefficient.

The effect of saturation of the leakage flux is explained by a significant increase in the stator and the rotor generator currents during the transient process [7]. It has a significant impact on the operation mode of the equipment. To present the effect of saturation of the leakage flux (Fig. 2), reactive resistances of the stator and the rotor $(X l s, X l r)$ are divided into their saturated components $(X l s-s, X l r-s)$ and unsaturated components $(X l s-u, X l r-u)$.

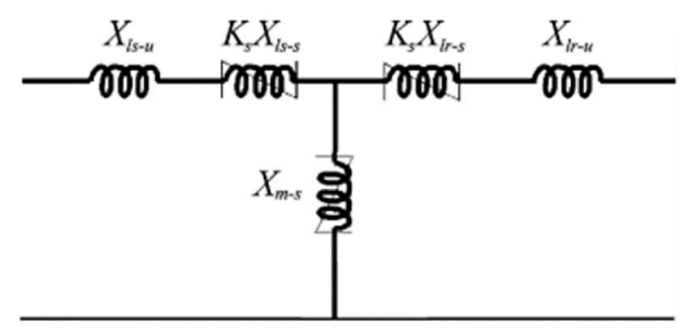

FIGURE 2. Equivalent scheme with regard to saturation

In this case, $K s$ can be found by the formula [8]:

$$
K_{s}=\left\{\begin{array}{cc}
1.0, & i \leq i_{\text {sat }} \\
\frac{2}{\pi}\left[\tan ^{-1}\left(\frac{\gamma}{\sqrt{1-\gamma}}\right)\right]+\gamma \sqrt{1-\gamma}, & i>i_{\text {sat }}
\end{array}\right.
$$

\section{CONCLUSION}

The analysis of various DFIG models has led to the conclusion that to assess the impact of wind power plants on the operating mode of power systems, at least the 7 th order model is necessary, taking into account the saturation of 
main and leakage fluxes of an electric machine. In addition, it was determined that the model of the $3 \mathrm{rd}$ order is unacceptable for solving the tasks.

\section{ACKNOWLEDGMENTS}

The work was supported by Ministry of Science and Higher Education of Russian Federation, according to the research project No. MK-1675.2019.8.

\section{REFERENCES}

1. M. Fujimitsu, T. Komatsu, K. Koyanagi, K. Hu and R Yokoyama, PowerCon 2000 International Conference on Power System Technology, Conference Proceedings (Perth, WA, Australia 2000), pp.25-30.

2. A. A. Suvorov, A. S. Gusev, A. O. Sulaymanov and O. V. Suslova, MATEC Web of Conf. 91, 1-4 (2017).

3. M.V. Andreev, A.S. Gusev, N.Yu. Ruban, A.A. Suvorov, R.A. Ufa, A.B. Askarov, J.Bemš and T.Králík, IEEE Transactions on Power Systems 34 (2), 1404-1415 (2019)

4. H.Knudsen and V.Akhmatov, "Induction generator models in dynamic simulation tools" in International Conference on Power System Transients IPST'99, Conference Proceedings (Budapest, Hungary, 1999), pp. 253259.

5. V. Akhmatov, Journal of Wind Engineering 26 (2), 85-108 (2002).

6. V. Akhmatov, "Modelling of variable-speed wind turbines with doubly-fed induction generators in short-term stability investigations" in 3rd Int. Workshop on Transmission Networks for Offshore Wind Farms, (Stockholm, Sweden, 2002), pp. 460-465.

7. H.M. Jabr and N.C. Kar, Electric Power Systems Research 77(8), 1019-1027 (2007)

8. P. Kundur, Power System Stability and Control (McGraw-Hill, New York, 1993), p. 1199. 